\section{Positive Demand at Home and Abroad}

D espite a falling share of world trade, German suppliers continue to dominate the world market in surface technology. Since the crisis of 2009, the surface technology industry in Germany has made a good recovery. In 2010, production reached a volume of around EUR 1.3 billion (+4 \%).

The world trade (after exports) in surface technology amounted to EUR 2.8 billion (+27\%) in 2010. Because of poor growth in German exports, direct deliveries from Germany to other countries fell to $20 \%$ of the total volume of world trade. In contrast, Chinese exports grew significantly. For the first time, China has moved up to second place in the list of countries that export surface technology, with a $17 \%$ share of the world market. However, German suppliers' expertise in building plants and machinery means that their worldwide importance is much greater, because local suppliers play an essential role in machinery construction projects.

German companies are still the leaders when it comes to technology and they are continuing to exploit opportunities on the international market. German suppliers and those from elsewhere in Europe are also finding that new opportunities are opening up because of their extensive expertise in environmentally friendly surface technologies. This expertise is largely a result of the environmental regulations in Europe, which have become increasingly stringent over recent years. As a result, process technologies involving integrated measures, such as the use of low-solvent or solvent-free coatings, application systems with high levels of efficiency, recovery of overspray and other circulationbased processes, together with follow-up systems for recovering energy from solvents released during processes and for recycling solvents from process air, for example, have become widely used on the European market.

\section{Dürr continues its success story in China}

A cting as general contractor, Dürr is building a further Eco+Paintshop in Ningbo for SVW Shanghai, the joint venture between the Volkswagen Group and the Chinese SAIC Group. The new paint shop, which is designed to use a primer-free process and water-based paint, can produce up to 62 units per hour. The contract has a value of hundreds of millions of euros and was awarded in the fourth quarter of 2011. The paint shop will come into operation in August 2014 and will paint vehicles for Volkswagen and Skoda. Dürr's EcoDryScrubber, the innovative system for the dry separation of paint overspray, will once again be used in Ningbo. The company has chosen its rotating dip-coating system RoDip M for pretreatment and electrocoating. Dürr is equipping the lines for underbody protection with four robot stations that have a total of 26 EcoRS robots and application systems for automatic seam sealing, underbody protection and sill coating. In addition, an automatic cavity flood system for rustproofing body cavities forms part of the new plant. Before the base coat and clear coat are applied, the exterior of the bodies are cleaned with sword brushes by two EcoRS 60 robots. On each of the two lines, 32 EcoRP L133 painting robots paint the vehicle interiors and exteriors in a fully automated process. The EcoLCC linear colour changer used for the base coats significantly reduces paint wastage when the colour is changed.

\section{Chemetall opens a new production plant in India}

Chemetall has invested in a second state-of-the-art production plant in the city of Chennai in India. The new facility will substantially increase the company's current capacity in the region. "To keep pace with the growth dynamics of the Indian market, we have built our new facility in the heart of the automotive industry," explains Asis Ray, managing director of Chemetall-Rai. The new plant is intended to meet the increasing demand for local supply in the rapidly growing market. "The investment in our new plant is a further milestone in Chemetall's expansion strategy and it clearly demonstrates the importance of the Indian market for us," says Joris Merckx, managing director of Chemetall GmbH. Recently the company has acquired the speciality chemical business of Gramos, one of the major local suppliers of surface treatment technology to the Indian automotive industry. Chennai is the centre of an important region for the vehicle industry and its suppliers.

\title{
New BASF coating technology centre in India and new application centre in Mexico
}

A t the end of June 2012, BASF opened its new coating technical support lab in the Indian city of Mangalore. The employees at the new facility will provide lab services including product development, analytical testing, certification and new pigment qualification. The technical support lab will complement the existing expertise at the Mangalore site. In early July, BASF opened a new application centre for vehicle paints and an extension to the development laboratory at its production site in Tultitlán in Mexico. The aim is to provide improved technical support for the automotive industry in North America and to develop sustainable and customised coating technologies. Among other things, the new facility will offer technical services for base coats, pigments and dispersions and for introducing new colours. 